\title{
Nilai Dan Fondasi Pembangunan Ekonomi Dalam Islam
}

\author{
Masrizal \\ Fakultas Ekonomi dan Bisnis, Universitas Airlangga \\ Email: masrizalrizal95@gmail.com \\ Sitti Hamidah Mujahidah \\ Fakultas Ekonomi dan Bisnis, Universitas Airlangga \\ Email: sitti.hamidah-2017@pasca.unair.ac.id \\ Afifah Nur Millatina \\ Fakultas Ekonomi dan Bisnis, Universitas Airlangga \\ Email:milea1903@gmail.com \\ Sri Herianingrum \\ Fakultas Ekonomi dan Bisnis, Universitas Airlangga \\ Email: sriheria@gmail.com
}

\begin{abstract}
Abstrak:
Economic development in Islam is a balance and sustainable in terms of material or nonmaterial resulting from Islamic morals. The aim is not merely material welfare in the world, but also the welfare of the hereafter. This paper explains the value and basis of economic development. The basis and value of economic development in Islam consists of tauhid, rububiyah, khilafah and tazkiyah. The principle of tauhid representing all human activities in the form of human resources (muámalah) is framed with the support of relations with God. The Rububiyah principle from God is a god who creates nature, devotes, supports, gives sustenance, everything under his knowledge, skill and understanding that is infinite. The principle of khilafah as a human being, which prosper the earth and become the responsible to Allah, and manage the resources, that are mandated to support and tazkiyah to purify humans in assistance with Allah, their fellowmen and the natural environment, society and country.

[Pembangunan Ekonomi dalam Islam merupakan keseimbangan dan berkelanjutan antara aspek materi maupun non materi yang dihasilkan dari moral-moral Islam. Tujuannya bukan semata-mata kesejahteraan material di dunia, tetapi juga kesejahteraan akhirat. Paper ini bertujuan untuk menjelaskan nilai dan dasar dalam pembangunan ekonomi. Dasar dan nilai pembangunan ekonomi dalam Islam terdiri dari tauhid, rububiyah, khilafah dan tazkiyah. Prinsip tauhid merupakan segala aktivitas manusia dalam hubungannya dengan alam dan sumber daya manusia (muámalah) dibingkai dengan kerangka hubungan dengan Allah. Prinsip rububiyah bahwa Allah ialah Tuhan yang menciptakan alam, memilikinya, memberi rezeki, alam dan segala isinya di bawah pengetahuan, kehendak dan kebijaksanaan-Nya yang tidak terhingga. Prinsip khilafah bahwa manusia sebagai wakil Allah SWT di muka bumi untuk memakmurkan bumi dan bertanggung jawab kepada Allah SWT tentang pengelolaan alam dan segala sumber daya yang diamanahkan kepadanya. Tazkiyah mensucikan manusia dalam hubungannya dengan Allah SWT, sesamanya dan alam lingkungan, masyarkat dan negara.]
\end{abstract}

Kata Kunci: Pembangunan Ekonomi; Manusia; Pondasi; Nilai. 


\section{PENDAHULUAN}

Pembangunan ekonomi (economic development) dan ekonomi pembangunan seringkali dipakai saling bergantian dengan pengertian yang sama, padahal dua istilah ini memiliki arti orientasi yang berbeda. Menurut Sukirno, ${ }^{1}$ pembangunan ekonomi diartikan sebagai serangkaian usaha dalam suatu perekonomian untuk mengembangkan kegiatan ekonominya sehingga infrastruktur lebih banyak tersedia, perusahaan semakin banyak dan semakin berkembang, taraf pendidikan semakin tinggi dan teknologi semakin meningkat. Sebagai implikasi dari perkembangan ini diharapkan kesempatan kerja akan bertambah, tingkat pendapatan meningkat, dan kemakmuran masyarakat semakin tinggi. Sedangkan ekonomi pembangunan adalah suatu bidang studi dan ilmu ekonomi yang mempelajari masalah-masalah ekonomi di negara-negara berkembang yang seterusnya akan dinamakan negara berkembang saja-dan kebijakan-kebijakan yang perlu dilakukan untuk mewujudkan pembangunan ekonomi. Hal senada juga dikemukakan oleh Huda "Economic development is the development of economic wealth of countries or regions for the well-being of their inhabitants. The study of economic development is known as development economics" (Pembangunan ekonomi adalah pembangunan kemakmuran ekonomi negara atau daerah guna kesejahteraan penduduknya. Studi tentang pembangunan ekonomi dikenal sebagai ekonomi pembangunan). ${ }^{2}$

Sementara menurut Nafán, ${ }^{3}$ Istilah pembangunan ekonomi (economic development) biasanya dikaitkan dengan perkembangan ekonomi di negara-negara berkembang. Sebagian ahli ekonomi mengartikan istilah ini sebagai "economic development is growth plus change" (pembangunan ekonomi adalah pertumbuhan ekonomi yang diikuti oleh perubahanperubahan dalam struktur dan corak kegiatan ekonomi). Dengan kata lain, dalam mengartikan istilah pembangunan ekonomi, ekonom bukan saja tertarik kepada masalah perkembangan pendapatan nasional rill, tetapi juga kepada modernisasi kegiatan ekonomi, misalnya kepada usaha perombakan sektor pertanian yang tradisional, mempercepat pertumbuhan ekonomi dan pemerataan pendapatan. Dari definisi di atas, dapat ditarik kesimpulan bahwa pembangunan ekonomi merupakan suatu proses yang menyebabkan pendapatan rill perkapita penduduk suatu negara dalam jangka panjang yang disertai oleh perbaikan sistem kelembagaan. ${ }^{4}$ Dalam kajian ekonomi, kedua istilah tersebut terkadang digunakan dalam konteks yang hampir sama. Banyak orang mencampuradukkan penggunaan kedua istilah tersebut. Pencampuradukan istilah ini walaupun tidak dapat dibenarkan, pada dasarnya tidak terlalu memengaruhi kajian ekonomi, karena inti pembahasan akhirnya akan berhubungan erat dengan perkembangan perekonomian suatu negara.

Dalam berbagai literatur tentang ekonomi Islam, kedua istilh ini juga ditemukan. Ekonomi Islam pada dasarnya memandang bahwa pertumbuhan ekonomi adalah bagian dari pembangunan ekonomi. Pertumbuhan ekonomi didefinisikan dengan a suistained growth of a right kind of output which can contribute to human welfare. (Pertumbuhan terus-menerus dari faktor produksi secara benar yang mampu memberikan kontribusi bagi kesejahteraan manusia). Berdasarkan pengertian ini, maka pertumbuhan ekonomi menurut Islam merupakan hal yang sarat nilai. Suatu peningkatan yang dialami oleh faktor produksi tidak dianggap sebagai pertumbuhan ekonomi, jika produksi tersebut, misalnya memasukkan barang-barang yang terbukti memberikan efek buruk dan membahayakan manusia.

\footnotetext{
1 Sadono Sukirno, Ekonomi Pembangunan: Proses, Masalah, dan Dasar Kebijakan, Jakarta: Kencana, 2015, 15.

2 Nurul Huda, Ekonomi Pembangunan Islam. Jakarta: Kencana, 2015, 35.

3 Naf'an, Ekonomi Makro: Tinjauan Ekonomi Syariah. Yogyakarta: Graha Ilmu, 2014, 236.

4 Lincolin Arsyad, Ekonomi Pembangunan. Yogyakarta: UPPT STIM YKPN, 2016, 11.
} 
Sedangkan istilah pembangunan ekonomi yang dimaksudkan dalam Islam adalah the process of alleviating poverty and provision of ease, comfort and decency in life (Proses untuk mengurangi kemiskinan serta menciptakan ketentraman, kenyamanan dan tata susila dalam kehidupan). Dalam pengertian ini, maka pembangunan ekonomi menurut Islam bersifat multi dimensi yang mencakup aspek kuantitatif dan kualitatif. Abulhasan M. Sadeq, ${ }^{5}$ mendefiniskan ekonomi pembangunan dalam Islam adalah keseimbangan dan berkelanjutan dalam hal materi maupun non materi yang lengkap dengan standar moral yang tinggi yang dihasilkan dari moral-moral Islam. Tujuannya bukan semata-mata kesejahteraan material di dunia, tetapi juga kesejahteraan akhirat. Keduanya menurut Islam menyatu secara integral. Pembangunan ekonomi hanyalah salah satu aspek dari pembangunan, dimana tujuan utamanya adalah untuk meningkatkan kehidupan individu, baik di dalam kehidupan dunia maupun akhirat. Jelas, pembangunan ekonomi dalam Islam tidak hanya berfokus pada perkembangan materi tetapi juga perkembangan spiritual dan aspek kehidupan duniawi maupun ukhrawi. ${ }^{6}$

\section{HASIL DAN PEMBAHASAN \\ PRINSIP PEMBANGUNAN EKONOMI ISLAM.}

Perkembangan ekonomi dan kemajuan dalam masyarakat manusia bergantung pada banyak faktor. Dapat dianggap bahwa memfokuskan hanya pada satu elemen dapat menyebabkan pemahaman yang tidak lengkap tentang proses pengembangan. ${ }^{7}$ Islam sangat memperhatikan masalah pembangunan ekonomi, namun tetap menempatkannya pada persoalan pembangunan yang lebih besar, yaitu pembangunan umat manusia. Fungsi utama Islam adalah membimbing manusia pada jalur yang benar dan arah yang tepat. Semua aspek yang berkaitan dengan pembangunan ekonomi harus menyatu dengan pembangunan ummat manusia secara keseluruhan. Islam memiliki pandangan eksklusif terhadap proses pembangunan. Pembangunan ekonomi dalam Islam ialah pembangunan yang meliputi semua aspek pembangunan kebendaan (ekonomi) dan pembangunan insan secara keseluruhan. Pertumbuhan ekonomi bukan hanya diukur dari aspek ekonomi, melainkan aktivitas manusia yang ditujukan untuk pertumbuhan dan kemajuan sisi material dan spiritual manusia sekaligus. $^{8}$

Pembangunan ekonomi dalam Islam bersifat komprehensif dan mengandung unsur spiritual, moral, dan material. Pembangunan merupakan aktivitas yang berorientasi pada tujuan dan nilai. Aspek materi, moral, ekonomi, sosial spiritual dan fisik tidak dapat dipisahkan. Kebahagiaan yang ingin dicapai tidak hanya kebahagiaan dan kesejahteraan material di dunia, tetapi juga di akhirat. Fokus utama pembangunan adalah manusia dengan lingkungan kulturalnya. Ini berbeda dengan konsep pambangunan ekonomi modern yang menegaskan bahwa wilayah operasi pembangunan adalah lingkungan fisik saja. Dengan demikian Islam memperluas wilayah jangkauan objek pemabngunan dari lingkungan fisik kepada manusia. Hal senada juga dikemukakan oleh Askari, dkk. konsep pembangunan Islam

\footnotetext{
${ }^{5}$ Abdulhasan M Sadaq. Development Issues in Islam. Kuala Lumpur: International Islamic University Malaysia, 2016.

6 Farhana Mohamad Suhaimi, Asmak Ab Rahman, Sabitha Marican, The role of share waqf in the socio-economic development of the Muslim community: The Malaysian experience", Humanomics, Vol. 30 Issue: 3, 228.

7 Sadr, Seyed Kazem, The role of human capital in economic development of the earliest Islamic period, International Journal of Islamic and Middle Eastern Finance and Management, Vol. 8 Issue: 4, 2015, 399.

${ }^{8}$ Fadllan, Fadllan. "REKONSTRUKSI PEMBANGUNAN EKONOMI BERBASIS ISLAM Telaah Pemikiran M. Umer Chapra." NUANSA: Jurnal Penelitian IImu Sosial dan Keagamaan Islam 15, no. 2 (2018): 393-426.
} 
bahwa manusia bukan hanya sebagai sarana melainkan juga dijadikan sebagai tujuan dalam pembangunan ekonomi. ${ }^{9}$

Para sarjana ekonomi Muslim memperluas ruang lingkup pembangunan untuk memasukkan perkembangan dunia material dan spiritual yang seimbang, dengan fokus pada penerapan nilai-nilai Islam sebagai dasar untuk perkembangan ini. Ekonom Islam modren seperti Khursid Ahmad, telah mengembangkan pendekaan multidisiplin dan multidimensi yang membentuk landasan konseptual di mana standar etika dan moral Islam terintegrasi erat dengan motif ekonomi. Bertentangan dengan ekonomi konvesional, pendekatan Islam modren ini menghadirkan visi sosial-etis ekonomi untuk memecahkan masalah manusia. ${ }^{10}$

Khursid Ahmad dalam Sayyid Tahir,11 merumuskan dasar-dasar filosofis pembangunan ekonomi ini yaitu: pertama tauhid, yang mengacu kepada pengakuan terhadap keesaan Allah dan kekuasaan-Nya yang menetapkan aturan hubungan antara manusia dengan Tuhan, dan manusia dengan manusia lainnya (habl-minallah wa habl min an-nas). Kedua Rububiyyah, ber-i'tiqad bahwa Allah SWT ialah Tuhan yang menciptakan alam, mengatur, memilikinya, memberi rezeki, segala sesuatu di bawah pengetahuan, kehendek dan kebijaksanaan-Nya yang tidak terhingga. Beriman bahwa hanya Allah SWT satu-satunya Tuhan yang memiliki, merencanakan, menciptakan, mengatur, memelihara, memberi rezeki, memberikan menfaat, menolak mudharat serta menjaga seluruh alam semesta. Ketiga khilafah, yang menyatakan bahwa manusia adalah wakil Allah di muka bumi untuk memakmurkan bumi dan bertanggung jawab kepada Allah SWT tentang pengelolaan sumber daya yang diamanahkan kepadanya, dan keempat tazkiyah, yaitu mensucikan manusia dalam hubungannya dengan Allah SWT, sesamanya dan alam lingkungan, masyarkat dan negara.

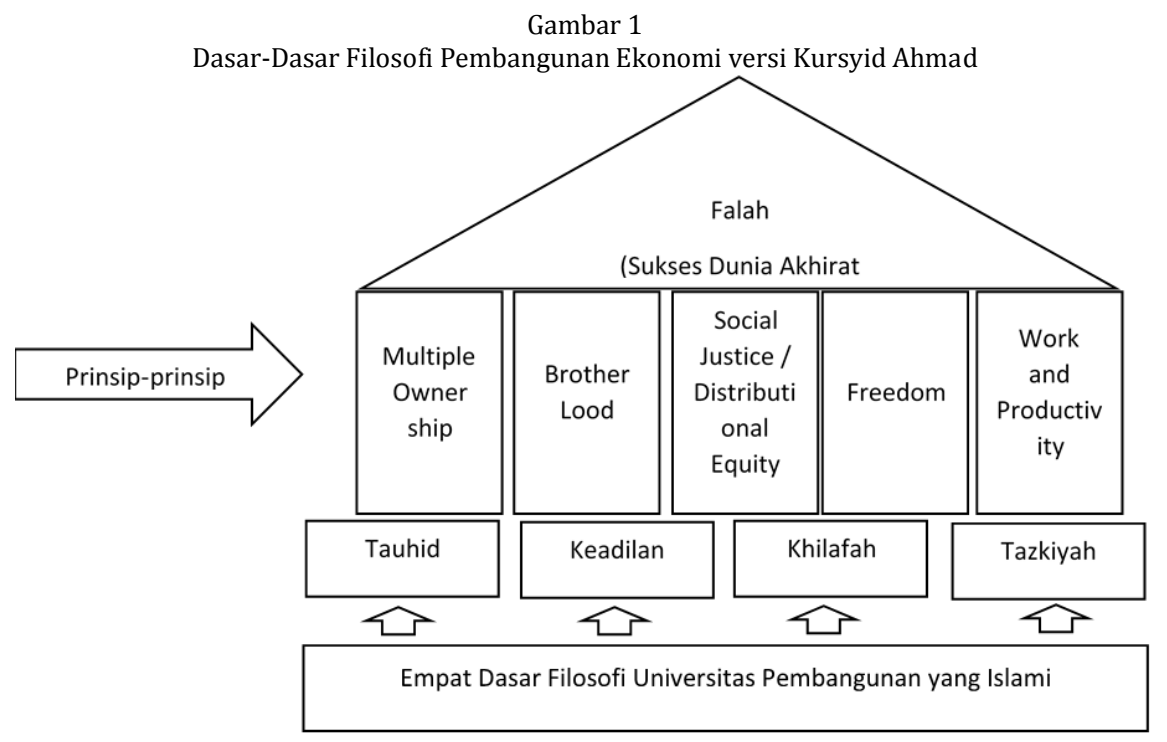

\footnotetext{
${ }_{9}$ Hossein Askari dkk, Understending Islam: Devlopment, Economic and Finance. Munich Personal Repec Archive, 2013, No. 56016.

10 Nasir Nabi Bhat, The Economic Thougt of Khurshid Ahmad, Turkish Journal of Islamic Economics, Vol. 3, No. 2, 2016, 4.

11 Sayyid Tahir. Islamic Perspectives on Economic Development. The Pakistan Devlopment Review,34:4 Part II, 1995, 845-856.
} 
Berdasarkan prinsip-prinsip fundamental dan nilai-nilai di atas, Khursid Ahmad,12 menguraikan hal-hal penting dari konsep pembangunan Islam sebagai berikut:

Pertama, pembangunan ekonomi dalam Islam bersifat komprehensif dan mengandung unsur spiritual, moral dan material. Pembangunan merupakan aktivitas yang berorientasi pada tujuan dan nilai. Aspek material. moral, ekonomi, sosial, spiritual, dan fisik tidak dapat dipisahkan. Kebahagiaan yang ingin dicapai tidak hanya kebahagiaan dan kesejahteraan material di dunia, tetapi juga di akhirat.

Kedua, fokus utama pembangunan adalah manusia dengan lingkungan kulturnya. Ini berbeda dengan konsep pembangunan ekonomi moderen yang menegaskan bahwa wilayah operasi pembangunan adalah lingkungan fisik saja. Dengan demikian, Islam memperluas jangkauan objek pembangunan.

Ketiga, pembangunan ekonomi adalah aktivitas mulitidimensi sehingga semua usaha harus diserahkan pada keseimbangan berbagai faktor dan tidak menimbulkan ketimpangan.

Keempat, pembangunan ekonomi melibatkan sejumlah perubahan, baik kualitatif dan kuantitatif, dan seimbangan antara satu sama lainnya.

\section{Konsep Tauhid}

Tauhid merupakan fondasi ajaran Islam. Islam bukan agama marginal yang berurusan dengan kehidupan spiritual saja. Islam adalah agama yang memberikan petunjuk dan kesejahteraan bagi kehidupan dunia dan akhirat. ${ }^{13}$ Dengan tauhid, manusia menyaksikan bahwa "tiada sesuatupun yang layak disembah selain Allah SWT," dan tidak ada pemilik langit, bumi dan isinya, selain Allah SWT," karena Allah SWT adalah pencipta alam semesta dan isinya, sekaligus pemiliknya, termasuk pemilik manusia dan seluruh sumber daya yang ada. Sebagaimana termaktub dalam firman-Nya surat al-Baqarah ayat 29:

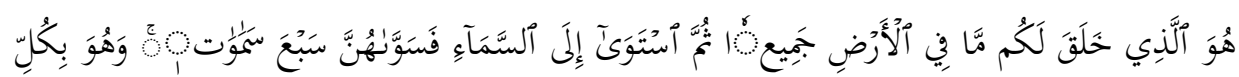

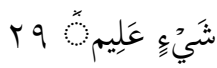

"Dialah Allah, yang menjadikan segala yang ada di bumi untuk kamu dan Dia berkehendak (menciptakan) langit, lalu dijadikan-Nya tujuh langit. Dan Dia Maha Mengetahui segala sesuatu." (QS. Al-Baqarah: 29).

Karena itu, Allah SWT adalah pemilik hakiki. Manusia hanya diberi amanah untuk "memiliki" sementara waktu, sebagai ujian bagi mereka. Dalam Islam, segala sesuatu yang ada tidak diciptakan dengan sia-sia, tetapi memiliki tujuan. Tujuan diciptakannya manusia adalah untuk beribadah kepada-NYA. Karena itu segala aktivitas manusia dalam hubungannya dengan alam dan sumber daya manusia (muámalah) dibingkai dengan kerangka hubungan dengan Allah. Karena kepada-NYA manusia akan mempertanggungjawabkan segala perbuatan, termasuk aktivitas ekonomi dan bisnis. ${ }^{14}$

Kegiatan ekonomi baik produksi, konsumsi, penukaran, dan distribusi diikatkan pada prinsip Ilahiah dan tujuan Ilahi. Oleh karena itu, seorang muslim merasa ketika bekerja, ataupun berdagang bahwa dengan amanah itu ia beribadah kepada Allah SWT. Semakin

\footnotetext{
12 Khursid Ahmad, Economic Development in Islam Framework", Studies in Islamic Economic, edited by Khoushid Ahmad, Islamic Research Fundation, Mashhad, 1980.

13 Necati Aydin, Islamic versus conventional human development index: empirical evidence from ten Muslim countries, International Journal of Social Economics, 2016.

${ }^{14}$ Akhmad Mujahidin, Ekonomi Islam: Sejerah, Konsep, Instrumen, Negara, dan Pasar. Jakarta: Rajawali Pers, 2014, 25.
} 
bertambah kebaikannya amalnya, semakin bertambah pula taqwa dan taqorrub-nya kepada Allah SWT. ${ }^{15}$

\section{Konsep Rububiyyah (keesaan dalam mengatur semesta alam)}

Mengesakan Allah SWT dalam penciptaan, pemberian rezeki, pemeliharaan alam semesta, penghancurannya, pencabutan nyawa dan pembangkitan manusia kembali, merupakan pengejawantahan dari keyakinan rububiyyah. Rububiyyah juga termasuk dalam pengaturan Ilahi untuk penyuburan, kesinambungan kehidupan dan mengarah segala makhluk menuju kepada kesempurnaannya.

Sifat rububiyyah juga mengandungi maksud kepada bimbingan seluruh apa yang Allah SWT ciptakan untuk menuju kebahagian (sa'adah) di dunia dan diakhirat. Firman Allah SWT dalam surah al-An'am ayat 164 yaitu;

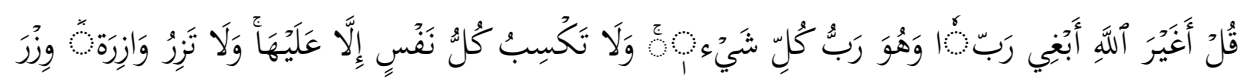

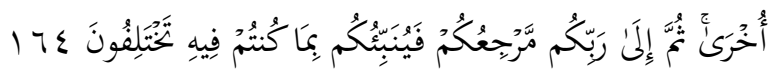

"Katakanlah: "Apakah aku akan mencari Tuhan selain Allah, padahal Dia adalah Tuhan bagi segala sesuatu. Dan tidaklah seorang membuat dosa melainkan kemudharatannya kembali kepada dirinya sendiri; dan seorang yang berdosa tidak akan memikul dosa orang lain. Kemudian kepada Tuhanmulah kamu kembali, dan akan diberitakan-Nya kepadamu apa yang kamu perselisihkan" (QS. Al-An'am: 164).

Makna kalimat Tuhan $(R a b)$ dalam ayat ini memberikan arti bahwa Allah SWT satusatunya Tuhan yang Mendidik, Menjaga, Mengatur, Mengurus sekalian alam semesta ini yang termasuk di dalamnya menguasai dan memiliki atas segala sesuatu. Sehingga ayat ini mewajibkan setiap muslim untuk bertawakkal dan mengikhlaskan segala aktivitas dalam kehidupan di dunia hanya untuk Allah SWT semata. Inilah hukum dasar alam yang menekankan kepada model pembangunan sumber yang berguna di samping mendorong dan berbagi sumber alam tersebut. Suatu tata cara yang telah Allah SWT tetapkan guna menjamin pembangunan sumber-sumber alam agar senantiasa seimbang dan berkelanjutan. Dalam konteks susunan yang suci inilah usaha manusia dalam hal pembangunan ekonomi dijalankan. ${ }^{16}$

\section{Konsep Khilafah}

Dalam Al-qurán Allah berfirman bahwa manusia diciptakan untuk menjadi pemimpin khalifah di bumi, artinya untuk menjadi pemimpin dan pemakmur bumi. Q.S Al-Baqarah ayat 30:

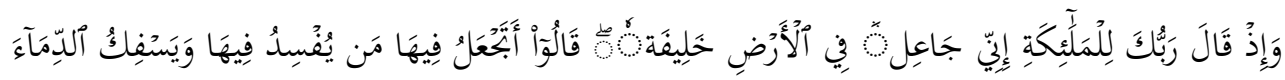

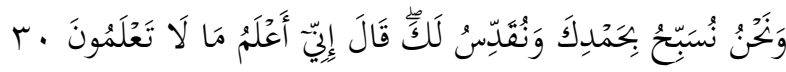

"Ingatlah ketika Tuhanmu berfirman kepada para Malaikat: "Sesungguhnya Aku hendak menjadikan seorang khalifah di muka bumi". Mereka berkata: "Mengapa Engkau hendak menjadikan (khalifah) di bumi itu orang yang akan

15 Yusuf Al-Qardhowi, Norma dan Etika Ekonomi Islam. Jakarta: Gema Insani Press, 2001, 220.

16 Syamsuri, Pradigma Pembangunan Ekonomi; Satu Analisis Tinjauan Ulang Dari Perspektif Ekonomi Islam, Islamiconomic: Jurnal Ekonomi Islam, 2016, Vol.7 No.2. 
membuat kerusakan padanya dan menumpahkan darah, padahal kami senantiasa bertasbih dengan memuji Engkau dan mensucikan Engkau?" Tuhan berfirman: "Sesungguhnya Aku mengetahui apa yang tidak kamu ketahui". (QS. Al-Baqarah: 30).

Oleh karena itu, pada dasarnya setiap manusia adalah pemimpin. Nabi Muhammad SAW bersabda: "Setiap dari kalian itu adalah pemimpin, dan akan dimintai pertanggung jawaban terhadap apa yang dipimpinnya". Fungsi utamanya adalah agar menjaga keteraturan interaksi (muamalah) antar kelompok- termasuk dalam bidang ekonomi agar kekacauan dan keributan dapat dihilangkan atau dikurangi.

Status khalifah atau pengemban amanat Allah SWT itu berlaku umum bagi semua manusia; tidak ada hak istimewa bagi individu atau bangsa tertentu sejauh berkaitan dengan tugas ke-khilafah-an itu. Namun ini tidak berarti bahwa umat manusia selalu atau harus memiliki hak yang sama untuk mendapatkan keuntungan dari alam semesta ini. Mereka hanya memiliki kesamaan hanya dalam hal kesempatan, dan setiap individu bisa mendapatkan individu bisa mendapatkan keuntungan itu sesuai dengan kemampuannya. Individu-individu diciptakan oleh Allah SWT dengan kemampuan yang berbeda-beda sehingga mereka secara instinktif diperintahkan untuk hidup bersama, bekerja sama dan saling memanfaatkan keterampilan mereka masing-masing. ${ }^{17}$

\section{Konsep Tazkiyah}

Tazkiyah yaitu mensucikan manusia dalam hubungannya dengan Allah SWT, sesamanya dan alam lingkungan, bangsa dan negara. Ibnu Taimiyah menjelaskan bahwa altazkiyah adalah menjadikan sesuatu menjadi suci baik zatnya maupun keyakinan dan fisiknya. Allah SWT mensifati orang-orang yang menyucikan jiwa itu dengan keberuntungan dan mensifati orang-orang yang mengotorinya dengan kerugian. Allah SWT berfirman dalam surat asy-Syams ayat 8-10:

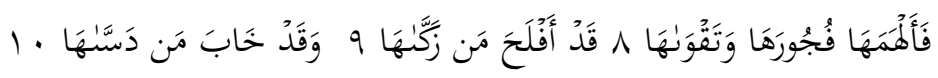

"Maka Allah mengilhamkan kepada jiwa itu jalan kefasikan dan ketaqwaannya. Sesungguhnya beruntunglah orang yang menyucikan jiwa itu dan sesungguhnya merugilah orang yang mengotorinya" (QS. Asy-Syams: 810).

Ibnu Jarir al-Thabari menafsirkan bahwa orang-orang yang beruntung adalah mereka yang Allah sucikan jiwanya dari kekufuran dan kemaksiatan, serta memperbaikinya dengan amal shaleh. Untuk mencapai kesucian dan keberuntungan tersebut, Ibnu Katsir menjelaskan bahwa manusia harus menempuh jalan yaitu mentaati Allah SWT, membersihkan jiwanya dari akhlak tercela serta membersihkan jiwa dari berbagai hal yang dapat menyebakan hina.

Tazkiyah artinya mensucikan atau pertumbuhan dan kebaikan. Secara epistimologi tazkiyah berarti kebersihan dan perlakuan yang memiliki metode dan teknik, sifatnya dari syariat, dan kesannya terhadap tingkah laku serta usaha untuk mencari keridhaan Allah SWT. Tugas para nabi yang diutus oleh Allah SWT tidak lain untuk menyempurnakan kesucian (tazkiyah) manusia dalam semua hubungannya. Misalnya hubungan manusia dengan Allah SWT, manusia dengan manusia lainnya, maupun dengan lingkungan, dan alam sekitar dalam konteks berbangsa dan bernegara. Sebagaimana Nabi Muhammad SAW diutus ke muka bumi,

17 Adiwarman Karim, Ekonomi Mikro Islami. Jakarta: PT Rajagrafindo Persada, 2015, 40. 
tidak lain untuk memperbaiki akhlak dalam rangka menyucikan ummatnya. Penyucian yang telah beliau lakukan dengan diutusnya beliau yaitu membersihkan akidah dari perbuatan syirik, menyucikan akhlak dari perbuatan keji dan mungkar yang telah menjadi tradisi kaum jahiliyyah, dan menyucikan harta dari perkara-perakara yang syubhat maupun gharar menuju harta yang halal dan thayyib (baik). Melalui konsep tazkiyah inilah manusia dapat mengembangkan dirinya yang akhirnya dapat membangunkan semua demensi kehidupannya termasuk dimensi ekonomi. Selanjutnya implikasi atau dampak dari konsep tazkiyah ini adalah falah yaitu kesejahteraan dan kemakmuran baik di dunia maupun di akhirat.

Khurshid Ahmad menegaskan bahwa konsep pembangunan yang Islami sebenarnya dapat ditarik dari konsep tazkiyah, yang berarti penyucian terhadap sikap dan hubungan tersebut di muka bumi. Hasil dari tazkiyah adalah falah, yaitu sukses di dunia maupun di akhirat.

Asas tazkiyah mencegah kepincangan sosial dan mewujudkan pemerataan yang bermuara pada keadilan. Kesemuanya itu akan mewujudkan pembangunan yang berkelanjutan. Konsep pembangunan berkelanjutan pada hakikatnya adalah pelaksanaan asas rububiyah, yakni asas pendidikan, pemeliharaan dan kontinuitas menuju kepada kesempurnaan, seperti sifat Ilahi. ${ }^{18}$

Dengan demikian, jika keempat nilai yang dirumuskan oleh Khursyid Ahmad ini dapat direalisasikan dalam pembangunan ekonomi yang dibangun di Indonesia, maka negara akan dengan mudah mewujudkan cita-cita bangsa, yaitu negara yang sejahtera dan berkeadilan.

Berdasarkan dasar-dasar filosofis di atas, dapat dijelaskan bahwa prinsip pembangunan ekonomi menurut Islam bersifat komprehensif dan mengandung unsur spiritual, moral, dan material. Pembangunan merupakan aktivitas yang berorientasi pada tujuan dan nilai. Aspek materi, moral, ekonomi, sosial spiritual dan fisik tidak dapat dipisahkan. Kebahagiaan yang ingin dicapai tidak hanya kebahagiaan dan kesejahteraan material di dunia, tetapi juga kebahagiaan di akhirat. Fokus utama pembangunan adalah manusia dengan lingkungan kulturalnya. Ini berbeda dengan konsep pambangunan ekonomi moderen yang menegaskan bahwa wilayah operasi pembangunan adalah lingkungan fisik saja. Dengan emikian Islam memperluas wilayah jangkauan objek pembangunan dari lingkungan fisik kepada manusia. ${ }^{19}$

Pembangunan ekonomi adalah aktivitas multidimensional sehingga semua usaha harus diserahkan pada keseimbangan berbagai faktor dan tidak menimbulkan ketimpangan. Pendekatan utama dalam pembangunan munurut Islam terletak pada pemanfaatan sumber daya yang telah diberikan Allah SWT kepada ummat manusia dan lingkungannya semaksimal mungkin. Selain itu, pemanfaatan sumberdaya tersebut melalui pembagian, peningkatan secara merata berdasarkan prinsip keadilan dan kebenaran. Islam menganjurkan sikap bersyukur dan bersikap adil, sangat menguntuk sikap kufur dan zhalim.

Dengan demikian, dapat dirumuskan prinsip pembangunan ekonomi perspektif Islam antara lain: 1) Pembangunan ekonomi dalam Islam bersifat komprehensif dan mengandung unsur spiritual, moral, dan material; 2) Fokus utama pembangunan adalah manusia dengan lingkungan kulturnya; 3) Pembangunan ekonomi adalah aktivitas multidimensional sehingga semua usaha harus diserahkan pada keseimbangan berbagai faktor dan tidak menimbulkan ketimpangan; 4) Penekanan utama dalam pembangunan manurut Islam, terletak pada

18 Fadlan, Fadlan. "KONSEP PEMBANGUNAN EKONOMI BERBASIS ISLAM (Sebuah Upaya Pembangunan Ekonomi Indonesia yang Adil, Makmur, dan Sejahtera)." Al-Ihkam: Jurnal Hukum \& Pranata Sosial 5, no. 2 (2012): 257-274.

19 Ibid., 257-274. 
pemanfatan sumber daya yang telah diberikan Allah SWT kepada ummat manusia dan lingkungannya semaksimal mungkin. ${ }^{20}$

M.A Mannan menilai bahwa konsep pembangunan dalam Islam memiliki keungulan dibandingkan konsep moderen tentang pembangunan. Keunggulan tersebut terletak pada motivasi pembangunan ekonomi Islami, tidak hanya timbul dari masalah ekonomi manusia semata, tetapi juga dari tujuan ilahi yang tertara dalam Al-Qur'an dan Hadist.

Harus diakui bahwa pertumbuhan perkapita sangat tergantung kepada sumber daya alam. Namun sumber daya alam saja bukan syarat yang cukup untuk pembangunan ekonomi. Masih dibutuhkan syarat lain yang amat penting yaitu perilaku manusia. Perilaku manusia mempunyai peran yang sangat utama dalam pembangunan ekonomi. Oleh karena itu, harus ada upaya menempa perilaku manusia ke arah yang mendukung pembangunan. Dalam hal ini negara-negara muslim pada dasarnya lebih berpotensi dan tidak mengalami kesulitan seperti dialami oleh negara-negara sekuler dalam upaya menempa perilaku manusia tersebut.

Khursyid Ahmad merumuskan tujuan kebijakan pembangunan dan target yang lebih spesifik untuk tujuan pembangunan yaitu: pertama, pembangunan sumber daya insani merupakan tujuan utama dari kebijakan pembangunan. Dengan demikian, harus diupayakan membangkitkan sikap dan apresiasi yang benar, pengambangan watak dan kepribadian, pendidikan dan latihan yang menghasilkan keterampilan, pengembangan ilmu dan riset serta peningkatan partisipasi.

Kedua, perluasan produksi yang bermanfaat. Produksi yang dimaksud bukan hanya sesuatu yang dapat dibeli orang kaya saja, namun juga bermanfaat bagi kepentingan umat manusia secara keseluruhan. Produksi barang-barang yang dilarang oleh Islam tidak akan diperkenankan, sedangkan yang bermanfaat untuk umat akan ditingkatkan. Dalam hal ini ada tiga hal yang diperioritaskan: 1) Produksi dan tersedianya bahan makanan dan kebutuhan pokok dalam jumlah yang melimpah, termasuk bahan-bahan konstruksi, jalan dan kebutuhan lainnya dengan harga yang cukup murah. 2), perlunya pertahanan dunia Islam di negaranegara Islam, maka dibutuhkan peralatan persejataan yang memadai. 3), Swasembada di bidang produksi kebutuhan primer.

Ketiga, perbaikan kualitas hidup dengan memberikan prioritas pada lima hal yaitu, 1) Terciptanya lapangan kerja dengan segala penataan struktural, teknologi, investasi, dan pendidikan. 2) Sistem keamanan nasional yang luas dan efektif yang menjamin kebutuhan dasar masyarakat. 3) Pembagian kekayaan dan pendapatan yang merata. 4) Pembangunan yang berimbang yakni harmonisasi antara daerah yang berbeda dalam satu negara dan antar sektor ekonomi. Desentralisasi ekonomi dan pembangunan yang tepat, bukan saja merupakan tuntunan keadilan tetapi juga diperlukan untuk kemajuan yang maksimum. 5) Teknologi baru yaitu berkembangnya teknologi tepat guna yang sesuai dengan kondisi, kebutuhan, aspirasi negara-negara, khususnya negara-negara muslim. Proses pembangunan yang mandiri hanya dapat terwujud jika negara tersebut sudah bebas dari bantuan asing serta mampu menguasai teknologi yang berkembang dalam lingkungan sosial dan alam yang berbeda, teknologi itu selanjutnya akan diadaptasikan dengan kreatifitas sendiri.

Masudul Alam Choudhury dalam bukunya Contributions to Islamic Economic Theory mengatakan bahwa ada lima prinsip dalam perekonomian Islam yang dibutuhkan dalam pembangunan yang dikenal dengan prisma ekonomi Islam. Kelima prinsip tersebut penulis uraikan sebagai berikut: ${ }^{20}$ Maya Masita Septiarini dan Sri Herianingrum. Analisis I-HDI (Islamic Human Development Index) di Jawa Timur.
Jurnal Ekonomi Syariah Teori dan Teapan, 2017, Vol. 04 No. 05. 


\section{Tauhid dan Persaudaraan}

Sebagai khalifah di bumi, manusia berkewajiban untuk memanfaatkan bumi dan kekayaan yang terkandung di dalamnya yang serba berkecukupan itu untuk sebesarbesarnya kemaslahatan umat, bukan untuk perorangan, karena setiap insan yang beriman mengakui bahwa kepemilikan mutlak adalah pada Allah SWT. Untuk mewujudkan prinsip tauhid dan persaudaraan, Islam melarang riba dalam segala bentuk dan manifestasinya. Secara tauhid, Allah SWT sebagai pemilik sumber daya ekonomi telah menentukan bahwa setiap kekayaan adalah untuk kepentingan seluruh umat manusia.

\section{Work and Productivity (W)}

Perintah bekerja telah Allah SWT wajibkan semenjak nabi yang pertama, Adam As. Sampai kepada nabi yang terakhir Muhammad SAW. perintah ini tetap berlaku kepada semua orang tanpa membeda-bedakan pangkat, status dan jabatan seseorang. Berikut dali dari AlQur'an dan Sunnah tentang kewajiban bekerja.

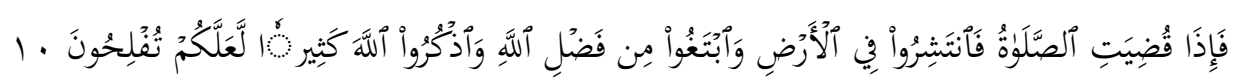

"Apabila telah ditunaikan shalat, maka bertebaranlah kamu di muka bumi; dan carilah karunia Allah dan ingatlah Allah sebanyak-banyaknya agar supaya kamu sekalian menjadi orang-orang yang beruntung." (QS. al- Jumah: 10).

Kerja dan produktifitas dalam perspektif Islam adalah untuk mencapai tiga sasaran, yaitu: 1) Mencukupi kebutuhan hidup (al-isyba') 2) Meraih laba yang wajar (al-irbah) 3) Menciptakan kemakmuran lingkungan baik sosial maupun alamiah.

\section{Coorporate}

Kerjasama dimaksudkan sebagai suatu usaha bersama antara orang perorangan atau kelompok manusia untuk mencapai satu atau tujuan bersama. Kerjasama (cooperation) adalah suatu usaha atau bekerja untuk mencapai suatu hasil. Kerjasama merupakan karakter yang penting dalam sistem ekonomi Islam. Nilai kerjasama ekonomi ini harus dapat dicerminkan dalam semua tingkatan kegiatan ekonomi, produksi, distribusi barang maupun jasa. Doktrin kerjasama dalam bidang ekonomi ini akan dapat menciptakan kerja produktif sehari-hari dari masyarakat, meningkatkan kesejahteraan, mencegah penindasan ekonomi dan distribusi ekonomi dan distribusi kekayaan yang tidak merata, dan melindungi kepentingan ekonomi dari pihak atau golongan ekonomi lemah.

\section{Ownership}

Prinsip ini adalah terjemahan dari nilai tauhid, pemilik primer langit, bumi dan seisinya adalah Allah SWT, sedangkan manusia diberi amanah untuk mengelolanya. Jadi, manusia dianggap sebagai pemilik sekunder. Konsep kepemilikan swasta diakui. Namun, untuk menjamin keadilan, yakni supaya tidak ada proses pen-zhalim-an sekelompok orang terhadap kelompok yang lain, maka cabang-cabang produksi yang penting dan menguasai hajat hidup orang banyak dikuasai oleh negara. Dengan demikian, kepemilikan negara dan nasionalisasi juga diakui. Sistem kepemilikan campuran juga mendapat tempat dalam Islam, baik campuran swasta-negara, swasta domestik-asing, atau negara-negara asing. Semua konsep ini berasal dari filosofi, norma, dan nilai-nilai Islam. 


\section{Distribution Equity}

Sistem ekonomi dalam Islam, berbagai permasalahan perekonomian telah dijamin dalam pengoptimalan distribusi, yaitu dengan cara menentukan tata cara kepemilikan, tata cara mengelola kepemilikan, serta mensuplai orang yang tidak sanggup untuk memenuhi kebutuhan hidupnya dengan harta yang bisa menjamin hidupnya dalam rangka mewujudkan keseimbangan dalam memenuhi kebutuhan-kebutuhannya di antara sesama. Dengan demikian, Islam telah memecahkan masalah buruknya distribusi tersebut. Instrumen zakat digunakan untuk menanggulangi kemiskinan dapat mencakup perluasan kesempatan kerja, kesejahteraan keluarga, rehabilitasi manusia usia lanjut, asuransi pengangguran, kompensasi bagi yang kekurangan ketika resesi dan depresi.

\section{PENUTUP}

Pembangunan Ekonomi dalam Islam merupakan keseimbangan dan berkelanjutan dalam hal materi maupun non materi yang dihasilkan dari moral-moral Islam. Adapun dasardasar filosofis yang islami sebagaimana dikemukakan oleh Khursyid Ahmad yaitu prinsip tauhid, rububiyah, khilafah, dan tazkiyah. Konsep pembangunan yang Islâmi sebenarnya dapat ditarik dari konsep tazkiyah, yang berarti penyucian terhadap sikap dan hubungan tersebut di muka bumi. Hasil dari tazkiyah adalah falah (kebahagiaan), yaitu sukses di dunia maupun di akhirat. Dengan demikian, dapat dirumuskan prinsip pembangunan ekonomi perspektif Islam antara lain: Pembangunan ekonomi dalam Islam bersifat komprehensif dan mengandung unsur spiritual, moral, dan material, Fokus utama pembangunan adalah manusia dengan lingkungan kulturnya, Pembangunan ekonomi adalah aktivitas multidimensional sehingga semua usaha harus diserahkan pada keseimbangan berbagai faktor dan tidak menimbulkan ketimpangan, Penekanan utama dalam pembangunan menurut Islam, terletak pada pemanfatan sumber daya yang telah diberikan Allah SWT kepada umat manusia dan lingkungannya semaksimal mungkin. Lima prinsip dalam perekonomian Islam yang dibutuhkan dalam pembangunan yang kemudian disebut dengan prisma ekonomi Islam menurut Masudul Alam Choudhury adalah tauhid, work and productivity, Corporate, Ownership, dan Distribution Equity.

\section{DAFTAR PUSTAKA}

Abdulhasan M Sadaq, Development Issues in Islam, Kuala Lumpur: International Islamic University Malaysia, 2006.

Adiwarman. A. Karim, Ekonomi Mikro Islami. Jakarta: PT Rajagrafindo Persada, 2015

Akhmad Mujahidin, Ekonomi Islam: Sejerah, Konsep, Instrumen, Negara, dan Pasar, Jakarta: Rajawali Pers, 2014

Fadllan, Fadllan. "REKONSTRUKSI PEMBANGUNAN EKONOMI BERBASIS ISLAM Telaah Pemikiran M. Umer Chapra." NUANSA: Jurnal Penelitian Ilmu Sosial dan Keagamaan Islam 15, no. 2 (2018): 393-426.

"KONSEP PEMBANGUNAN EKONOMI BERBASIS ISLAM (Sebuah Upaya Pembangunan Ekonomi Indonesia yang Adil, Makmur, dan Sejahtera).” Al-Ihkam: Jurnal Hukum \& Pranata Sosial 5, no. 2 (2012): 257-274.

Farhana Mohamad Suhaimi, Asmak Ab Rahman, Sabitha Marican, The role of share waqf in the socio-economic development of the Muslim community: The Malaysian experience, Humanomics, Vol. 30 Issue: 3, pp.227-254, 2014.

Hossein Askari dkk, Understending Islam: Devlopment, Economic and Finance, Munich Personal Repec Archive. No. 56016, 2013.

Khursid Ahmad, Economic Development in Islam Framework, Studies in Islamic Economic, edited by Khoushid Ahmad, Islamic Research Fundation, Mashhad, 1980. 
Lincolin Arsyad, Ekonomi Pembangunan. Yogyakarta: UPPT STIM YKPN, 2016.

Maya Masita Septiarini dan Sri Herianingrum. Analisis I-HDI (Islamic Human Development Index) di Jawa Timur. Jurnal Ekonomi Syariah Teori dan Teapan. Vol. 04 No. 05, 2017.

Naf'an, Ekonomi Makro: Tinjauan Ekonomi Syariah. Yogyakarta: Graha Ilmu, 2014

Nasir Nabi Bhat. The Economic Thougt of Khurshid Ahmad. Turkish Journal of Islamic Economics, Vol. 3, No. 2,2016.

Necati Aydin, Islamic versus conventional human development index: empirical evidence from ten Muslim countries, International Journal of Social Economics, 2016

Nurul Huda, Ekonomi Pembangunan Islam. Jakarta: Kencana, 2015.

Rasem N Kayed, M. Kabir Hassan, Saudi Arabia's economic development: entrepreneurship as a strategy, International Journal of Islamic and Middle Eastern Finance and Management, Vol. 4 Issue: 1, pp.52-73, 2011.

Sadono Sukirno, Ekonomi Pembangunan: Proses, Masalah, Dan Dasar Kebijakan, Jakarta: Kencana, 2015.

Sayyid Tahir, Islamic Perspectives on Economic Development. The Pakistan Devlopment Review. 34:4 Part II, 1995.

Seyed Kazem Sadr, The role of human capital in economic development of the earliest Islamic period", International Journal of Islamic and Middle Eastern Finance and Management, Vol. 8 Issue: 4, 2015.

Syamsuri, Pradigma Pembangunan Ekonomi; Satu Analisis Tinjauan Ulang Dari Perspektif Ekonomi Islam, Islamiconomic: Jurnal Ekonomi Islam, Vol.7 No.2, 2016.

Yusuf Al-Qardhowi, Norma dan Etika Ekonomi Islam, Jakarta: Gema Insani Press, 2001 